\title{
U(VI) reduction by spores of Clostridium acetobutylicum
}

\author{
Elena Dalla Vecchia ${ }^{\text {a,*}}$, Harish Veeramani ${ }^{\text {a,1, Elena I. Suvorova }}{ }^{\text {a }}$, Nicholas S. Wigginton ${ }^{\text {a,2 }}$, \\ John R. Bargar ${ }^{b}$, Rizlan Bernier-Latmani ${ }^{\text {a }}$ \\ a Environmental Microbiology Laboratory, Ecole Polytechnique Fédérale de Lausanne (EPFL), Lausanne, CH 1015, Switzerland \\ ${ }^{\mathrm{b}}$ Stanford Synchrotron Radiation Lightsource, 2575 Sand Hill Road, Menlo Park, CA 94025, USA
}

Received 4 June 2010; accepted 31 August 2010

Available online 21 September 2010

\begin{abstract}
Vegetative cells of Clostridium acetobutylicum are known to reduce hexavalent uranium (U(VI)). We investigated the ability of spores of this organism to drive the same reaction. We found that spores were able to remove U(VI) from solution when $\mathrm{H}_{2}$ was provided as an electron donor and to form a U(IV) precipitate. We tested several environmental conditions and found that spent vegetative cell growth medium was required for the process. Electron microscopy showed the product of reduction to accumulate outside the exosporium. Our results point towards a novel $\mathrm{U}(\mathrm{VI})$ reduction mechanism, driven by spores, that is distinct from the thoroughly studied reactions in metal-reducing Proteobacteria.
\end{abstract}

(C) 2010 Institut Pasteur. Published by Elsevier Masson SAS. All rights reserved.

Keywords: Spores; Uranium; Reduction; Bioremediation

\section{Introduction}

The release into the environment of radioactive material as a consequence of uranium mining, nuclear power generation and nuclear weapons production over the course of the last century has led to the contamination of a number of sites worldwide. This has given rise to notable efforts in the field of environmental science for the development of remediation strategies that aim at the limitation of the health hazard related to the chemical toxicity of uranium (Gavrilescu et al., 2009). In environments for which anoxic conditions can be maintained, a potential approach to addressing this problem is the precipitation of uranium by reducing highly soluble and

\footnotetext{
* Corresponding author.

E-mail addresses: elena.dallavecchia@epfl.ch (E.D. Vecchia), harish@ vt.edu (H. Veeramani), elena.suvorova@epfl.ch (E.I. Suvorova),nwiggint@ aaas.org (N.S. Wigginton), bargar@slac.stanford.edu (R. Bargar), rizlan. bernier-latmani@epfl.ch (R. Bernier-Latmani).

1 Present address: Department of Geosciences, Virginia Polytechnic Institute and State University (Virginia Tech), Blacksburg, VA 24061, USA.

2 Present address: Science, 1200 New York Avenue NW, Washington D.C., USA.
}

mobile U(VI) species to less soluble U(IV) species, generally dominated by the mineral uraninite $\left(\mathrm{UO}_{2}\right)$.

Since the discovery in the early nineties of direct microbial reduction of $\mathrm{U}(\mathrm{VI})$, bioremediation has become a potential and promising solution for uranium contamination (Lovley et al., 1991). Following this finding, a wide array of microbial species capable of reducing $\mathrm{U}(\mathrm{VI})$ has been identified, primarily among the dissimilatory metal- and sulfate-reducing bacteria (Wall and Krumholz, 2006). The bioremediation strategy relies on the in situ stimulation of indigenous bacterial communities by providing a suitable electron donor, in order to enhance the reduction of U(VI) (Lovley and Phillips, 1992).

The biochemical mechanisms of microbial U(VI) reduction have been extensively studied for organisms belonging to the Desulfovibrio (Payne et al., 2004), Shewanella (BencheikhLatmani et al., 2005), Geobacter (Shelobolina et al., 2007) and Anaeromyxobacter (Wu et al., 2006) genera. However, these biochemical models may not apply to the whole spectrum of bacteria capable of this reaction, which comprises not only many other mesophilic Proteobacteria, but also Firmicutes - both sulfate-reducing and fermentative - e.g., Clostridium spp. (Francis et al., 1994), Desulfotomaculum spp. 
(Tebo and Obraztsova, 1998), Desulfosporosinus spp. (Suzuki et al., 2004), extremophiles (e.g., Thermoanaerobacter spp. (Roh et al., 2002) and Pyrobaculum islandicum (Kashefi and Lovley, 2000)) as well as Gram-positive non-spore-forming bacteria (e.g., Thermoterrabacterium sp.) (Khijniak et al., 2005). Also, among this variety of U(VI)-reducing bacteria, a subset (e.g., Anaeromyxobacter dehalogenans (Wu et al., 2006), Geobacter metallireducens, Shewanella putrefaciens (Lovley et al., 1991) and Desulfotomaculum reducens (Tebo and Obraztsova, 1998)) have been reported to conserve energy from this reaction, and to couple it to growth.

Environmental microbial community analyses have shown that Gram-positive bacteria are represented in several U(VI)contaminated sites, suggesting the potential relevance of these strains in the remediation process (Chang et al., 2001; Suzuki et al., 2002, N'Guessan et al., 2008, Dong et al., 2006). Therefore, recent research has focused on the characterization of U(VI) reduction by Clostridium spp. and Desulfotomaculum spp. (Gao and Francis, 2008; Junier et al., 2009). The physiological characterization of $D$. reducens unveiled an unexpected mechanism of reduction: spores, in addition to vegetative cells, can catalyze U(VI) reduction (Junier et al., 2009). In the present manuscript, we address one of the fundamental questions raised by this novel finding: is the ability of spores to reduce $\mathrm{U}(\mathrm{VI})$ exclusive to $D$. reducens or do other related genera have similar capabilities? We chose to investigate Clostridium acetobutylicum because vegetative cells of this microorganism are known to be able to enzymatically drive the reduction ( $\mathrm{Gao}$ and Francis, 2008); however, the activity of spores had not been tested. In this work, we show that the spores of $C$. acetobutylicum are also capable of U(VI) reduction, but that vegetative cell spent growth medium is needed for the reduction to proceed. Thus, a factor produced by growing cells is released in the spent medium and is required for the process, but its identity remains unknown. Additionally, the localization of reduced uranium on the surface of the spore provided additional evidence of the direct involvement of spore proteins in the reduction. The ability of spores of both $D$. reducens and C. acetobutylicum to reduce $\mathrm{U}(\mathrm{VI})$ suggests the existence of novel metal reduction mechanisms, which could be shared or distinct among these two microorganisms, and reveals a potentially greater impact of bacterial spores on their surrounding environment than previously envisioned.

\section{Materials and methods}

All reagents were purchased from Sigma-Aldrich, unless otherwise indicated.

\subsection{Cellular culture, growth and sporulation}

C. acetobutylicum (DSM 792) was obtained from DSMZ. It was grown anaerobically in a medium modified from Francis et al. (1994), the main modification being a lower phosphate concentration to avoid uranium precipitation as a uranylphosphate phase. For this reason, we named the modified medium Francis low phosphate (FLP) basal medium, which is composed of (per liter): $\mathrm{CaCl}_{2}, 0.5 \mathrm{~g} ; \mathrm{K}_{2} \mathrm{HPO}_{4}, 0.03 \mathrm{~g} ; \mathrm{NH}_{4} \mathrm{Cl}$, $0.5 \mathrm{~g} ; \mathrm{MgSO}_{4}, 0.2 \mathrm{~g} ; \mathrm{FeSO}_{4}, 2.8 \mathrm{mg}$; glucose, $5 \mathrm{~g}$; glycerol, $0.25 \mathrm{~mL}$; peptone, $0.1 \mathrm{~g}$; yeast extract, $0.1 \mathrm{~g}$. pH was set at 6.8 , and cultures were incubated at $30^{\circ} \mathrm{C}$.

Sporulation of cells was induced by heat shock. The cultures were alternatively incubated at $40{ }^{\circ} \mathrm{C}$ (for $23 \mathrm{~h}$ ) and at $4{ }^{\circ} \mathrm{C}$ (for $1 \mathrm{~h}$ ), until at least $50 \%$ of the cells had sporulated. Spores were subsequently harvested by centrifugation at $7000 \times g$, for $15 \mathrm{~min}$ and rinsed with oxic Milli-Q (MQ) water in order to kill residual vegetative cells by combined oxygen and osmotic shock. Other sporulation approaches were also tested but did not result in a high yield of spores with the ability to reduce $\mathrm{U}(\mathrm{VI})$. Specifically, cells that were heatshocked for $15 \mathrm{~min}$ at $80{ }^{\circ} \mathrm{C}$ and incubated at $23{ }^{\circ} \mathrm{C}$ according to a protocol by Yang et al. (2009) produced spores that did not reproducibly reduce $\mathrm{U}(\mathrm{VI})$. Additionally, cells allowed to sporulate naturally gave a low spore yield, but those spores had the ability to reduce U(VI).

Desulfotomaculum reducens MI-1 was also cultured in WLP medium to obtain the spent medium for U(VI) reduction experiments (see following section). Growth conditions and WLP medium are described in Junier et al. (2009).

\subsection{Uranium reduction experiments}

All manipulations were carried out inside an anaerobic glovebox (COY Laboratory Products, Inc., Grass Lake, MI).

Vegetative cells were grown in FLP medium either buffered with $20 \mathrm{mM}$ 2-(N-morpholino)ethanesulfonic acid (MES) or unbuffered. At the end of the exponential growth phase $\left(\mathrm{OD}_{600}=0.7\right)$, the cell suspension was amended with $30 \mathrm{mM}$ bicarbonate and $100 \mu \mathrm{M} \mathrm{U}(\mathrm{VI})$ as uranyl acetate (from a $20 \mathrm{mM}$ anaerobic stock solution); in addition, the unbuffered cultures were amended with either $20 \mathrm{mM}$ MES buffer, or with $20 \mathrm{mM}$ piperazine-N,N'-bis(2-ethanesulfonic acid) (PIPES). $\mathrm{H}_{2}$ produced during growth served as the electron donor for the reduction. The capacity of vegetative cells to reduce $\mathrm{U}(\mathrm{VI})$ during growth was also tested, by amending FLP with MES, bicarbonate and $\mathrm{U}(\mathrm{VI})$ at the time of inoculation.

$\mathrm{U}(\mathrm{VI})$ reduction by spores was tested under different conditions. The chemical matrices used were the following: fresh FLP; spent FLP medium from $C$. acetobutylicum growth; spent WLP medium, obtained from the growth of D. reducens; bicarbonate-PIPES solution (BP). Fresh FLP was obtained by amending FLP basal medium, deprived of organic nutrients to avoid spore germination, with $20 \mathrm{mM}$ PIPES buffer and $30 \mathrm{mM}$ bicarbonate. Spent FLP was recovered by separating the supernatant from the pellet after centrifugation of a C. acetobutylicum culture in the stationary phase. Subsequently the supernatant was filter-sterilized (pore size $0.2 \mu \mathrm{m}$ ) inside the anaerobic chamber, collected in a fresh sterile container and amended with $20 \mathrm{mM}$ PIPES buffer and $30 \mathrm{mM}$ bicarbonate. Spent WLP was obtained in a similar manner, but no amendment was necessary since PIPES and bicarbonate were already present in the growth medium. BP was composed of $20 \mathrm{mM}$ PIPES and $30 \mathrm{mM}$ bicarbonate. In each case, $10^{7}$ spores $/ \mathrm{mL}$ were added to the medium and an 
amendment of $100 \mu \mathrm{M} \mathrm{U}(\mathrm{VI})$ (as uranyl acetate) and of $20 \mathrm{mM} \mathrm{H}_{2}$ was made.

In all experiments, U(VI) concentrations were measured over time by kinetic phosphorescence analysis (KPA-11; Chemcheck Instruments, Richland, WA) or by inductively coupled plasma optical emission spectrometry (ICP OES, Perkin Elmer Plasma) after anaerobic filtration (Millipore Millex-GV PVDF $0.2 \mu \mathrm{m})$.

\subsection{Transmission electron microscopy}

After reduction, $C$. acetobutylicum spores were fixed in $2.5 \%$ gluteraldehyde and sequentially dehydrated in pure grade ethanol (Fluka) series $(25 \%, 50 \%, 75 \%, 90 \%, 100 \%)$. The fixed dehydrated spores were collected by centrifugation and embedded in LR-white resin (Electron Microscopy Science, Hatfield, PA, USA), then polymerized for $24 \mathrm{~h}$ at $60{ }^{\circ} \mathrm{C}$. In order to avoid oxidation of the product of reduction, fixation, dehydration and embedding were carried out inside the anaerobic chamber. The polymerized resin was thin-sectioned with an ultracut ultramicrotome (Reichert-Jung) and an ultrasonic (oscillating) $35^{\circ} \mathrm{knife}$ from Diatome (Biel, Switzerland). Thin sections were then placed on copper grids (Quantifoil Micro Tools, GmbH Jena) and observed in an FEI CM300UT/ FEG microscope (Eindhoven, Netherlands). The analysis was done by conventional transmission electron microscopy (TEM), scanning transmission electron microscopy (STEM) and X-ray energy dispersive spectroscopy (EDS) with an INCA system (Oxford, UK).

\subsection{X-ray absorption spectroscopy}

Samples were analyzed by X-ray absorption near-edge structure (XANES) spectroscopy. Pelleted samples were sealed in anaerobic containers $\left(2-5 \% \mathrm{H}_{2}: 98-95 \% \mathrm{~N}_{2}\right)$ and shipped to the Stanford Synchrotron Radiation Lightsource (SSRL) for anaerobic loading and analysis. Samples were loaded in Al sample holders with Kapton windows under anoxic conditions in an anaerobic chamber, where they were stored until analysis. For analysis, the samples were mounted in a liquid $\mathrm{N}_{2}$ cryostat, placed under a vacuum and frozen at 77 K. Si (220) double-crystal monochromators detuned to

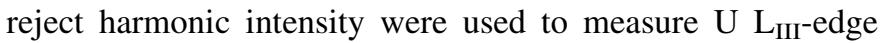
transmission or fluorescence spectra at the SSRL beamline 112. Vertical slits were used to maintain energy resolution at less than the natural line-width of the $\mathrm{U}_{\mathrm{III}}$-edge $(8.67 \mathrm{eV})$.

\section{Results}

\subsection{Uranium reduction by $C$. acetobutylicum vegetative cells}

U(VI) reduction experiments with vegetative cells of C. acetobutylicum were carried out by amending fermentatively-grown cultures with uranyl acetate at the end of the exponential growth phase $\left(\mathrm{OD}_{600} \sim 0.7\right)$ rather than growing the cells in the presence of U(VI). This is because, as reported by Francis et al. (1994) and confirmed in this work, cell growth is inhibited by the presence of U(VI).

The dissolved U(VI) concentration measured over time showed almost complete (95-97\%) removal of U(VI) from solution over a course of $65 \mathrm{~h}$ under all experimental conditions (Fig. 1) However, in the culture grown in the presence of MES buffer, most of the disappearance of U(VI) from solution ( $\sim 90 \%$ ) occurred within the first $30 \mathrm{~h}$. In all the cultures, the removal stemmed from enzymatic U(VI) reduction (Gao and Francis, 2008) as confirmed by XANES (Fig. 2). A negative control of spent medium in the absence of cells confirmed that the removal was cell-dependent (Fig. 1).

\subsection{Uranium reduction by the spores of \\ C. acetobutylicum}

We tested the U(VI) reduction activity of spores of C. acetobutylicum in several different media. One medium was spent FLP medium, which was collected at the end of exponential growth phase after the fermentative substrates had been completely converted to the final products: butyric acid, acetic acid, $\mathrm{CO}_{2}$ and $\mathrm{H}_{2}$ (Francis et al., 1994). The spent medium was amended with $\mathrm{H}_{2}$ to compensate for loss of the gas during spent medium recovery. The $30 \mathrm{mM}$ bicarbonate amendment ensured the complexation of U(VI) to this ion, rather than to the organic acid products of growth. The concentration of $\mathrm{U}(\mathrm{VI})$ in solution decreased steadily in the presence of spores until complete removal after $\sim 200 \mathrm{~h}$ (Fig. 1). Light microscopy showed that no germination event occurred during this time, as expected. The removal of U(VI)

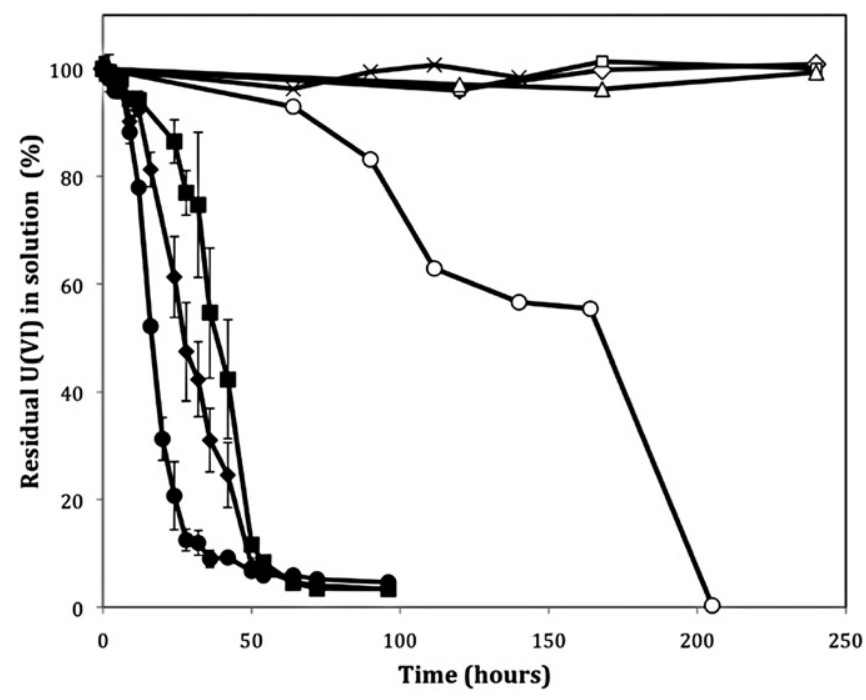

Fig. 1. U(VI) reduction by vegetative cells (filled symbols) and spores (open symbols). Spores only reduced in spent FLP medium (open circles), while vegetative cells reduced in all cases: in FLP amended with MES at the time of inoculation (filled circles); in FLP amended with MES (filled squares) or PIPES (filled diamonds) at the end of exponential phase. No reduction by spores was observed in fresh FLP (open squares), spent WLP (open diamonds) or BP solution (open triangles). Abiotic control of spent FLP also did not show any reductive activity (star). Note that there is substantial overlap for some of the data indicated by the open symbols (triangle, diamond, square) and the stars. 


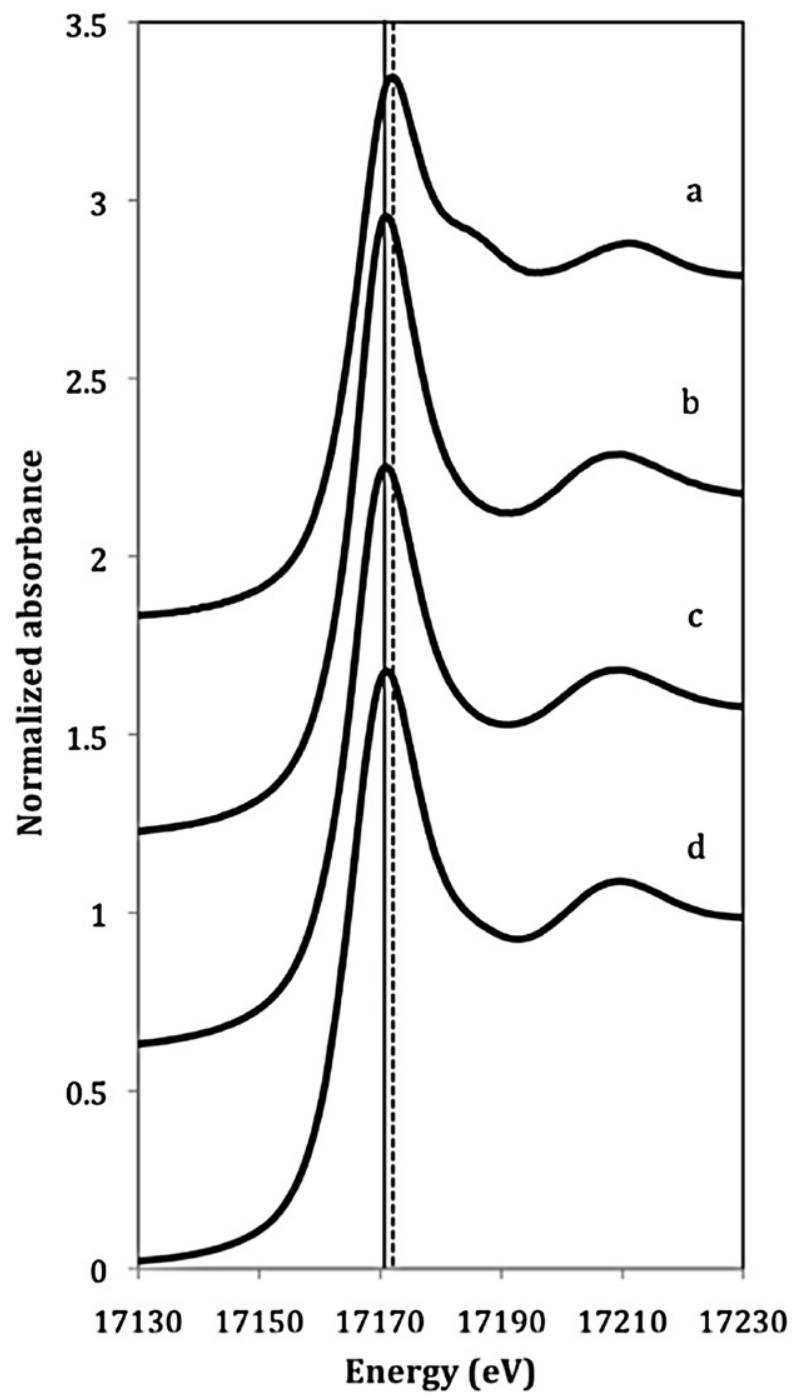

Fig. 2. U L LII-edge XANES spectra. (a) Autunite spectrum, U(VI) standard; (b) product of $\mathrm{U}(\mathrm{VI})$ reduction by spores of $C$. acetobutylicum;; (c) product of $\mathrm{U}(\mathrm{VI})$ reduction by vegetative cells of $C$. acetobutylicum; (d) $\mathrm{UO}_{2}$ spectrum, U(IV) standard. Note the position of the edge is identical for the two samples and the U(IV) standard (solid vertical line) but that the U(VI) standard (dashed vertical line) is shifted to higher energies.

proceeded at a notably slower rate than in the case of vegetative cells. The slow kinetics of the disappearance from solution suggests that the removal was not caused by physical processes such as adsorption onto the spore surface. Additionally, the spore suspensions became increasingly grayer as the U(VI) was removed from solution, suggesting the precipitation of a dark compound. This observation hinted at the reduction of $U(V I)$ to $U(I V)$, possibly in the form of the mineral $\mathrm{UO}_{2}$, which is black. Reduction of U(VI) to U(IV) was verified by XANES spectroscopy. As shown in Fig. 2, the XANES spectra of spores and vegetative cells of $C$. acetobutylicum were qualitatively similar to the spectrum of U(IV) and distinct from that of U(VI).

Following this finding, we investigated whether the spores of $C$. acetobutylicum, like those of $D$. reducens, require a specific compound present only in spent FLP medium or if they are more versatile in terms of the chemical environment that sustains reduction. Therefore, we also tested U(VI) reduction in fresh FLP medium and in a very simple chemical matrix, the BP medium, in the presence of the electron donor, $\mathrm{H}_{2}$. No U(VI) disappearance was detected in either case (Fig. 1). Additionally, we tested U(VI) reduction by $C$. acetobutylicum spores in spent WLP medium, collected at the exhaustion of pyruvate by D. reducens cells. As in fresh FLP and BP, we measured no U(VI) reduction by C. acetobutylicum spores. Given the excess bicarbonate concentration in all chemical environments considered here, we expect $\mathrm{U}(\mathrm{VI})$ to be present in the form of carbonate species and thus to be equally bioavailable to the spores.

\subsection{Localization of the product of reduction}

Thin sections of resin-embedded spores which had reduced $\mathrm{U}(\mathrm{VI})$ were examined for the localization of reduced uranium. Uranium is an electron-dense element and is visible in unstained bright field electron micrographs as dark material. The uranium was associated primarily with the exosporium or was present, unbound, in the space between spores (Fig. 3). The X-ray EDS maps of elemental U distributions showed no evidence for its localization inside the spore (Fig. 3). This suggests that the enzyme(s) involved in U(VI) reduction in C. acetobutylicum may be localized in the exosporium. Additionally, the morphology of the spores associated with $\mathrm{U}$ appeared to be similar to that of U-free spores, suggesting that the reduction process does not cause obvious damage to spores.

\section{Discussion}

The capacity of Clostridium spp., among which C. acetobutylicum, to reduce U(VI) to U(IV) has been known for almost two decades (Francis et al., 1992; Gao and Francis, 2008). Species belonging to this genus were shown to enzymatically reduce U(VI) to U(IV). However, previous work either did not investigate the speciation of the final product of reduction (Gao and Francis, 2008) or focused on the reduction of U(VI) initially complexed with citrate (Francis and Dodge, 2008). The product of such a reduction is $\mathrm{U}(\mathrm{IV})$ that remains complexed with citrate and is thus a soluble form of U(IV) (Francis and Dodge, 2008). For reductive immobilization strategies, the target product is a sorbed or precipitated form of $\mathrm{U}$. In this study, we considered the reduction of U(VI) by vegetative cells of $C$. acetobutylicum in the absence of organic ligands such as citrate, in order to assess the potential for reductive precipitation of the metal. We found that, in the presence of vegetative cells of $C$. acetobutylicum, U(VI) disappeared from solution (Fig. 1). XANES analysis of the cell pellet showed that the removal of $\mathrm{U}(\mathrm{VI})$ from solution was due to its reduction to U(IV) (Fig. 2). Interestingly, we found that U(VI) inhibited cell growth, but could be reduced to U(IV) by resting cells under non-growth conditions. This is consistent with reports for other bacteria that carry out U(VI) reduction either as a fortuitous or a detoxifying activity (Suzuki and Banfield, 2004; Thomas et al., 2010; Wall and Krumholz, 2006). 


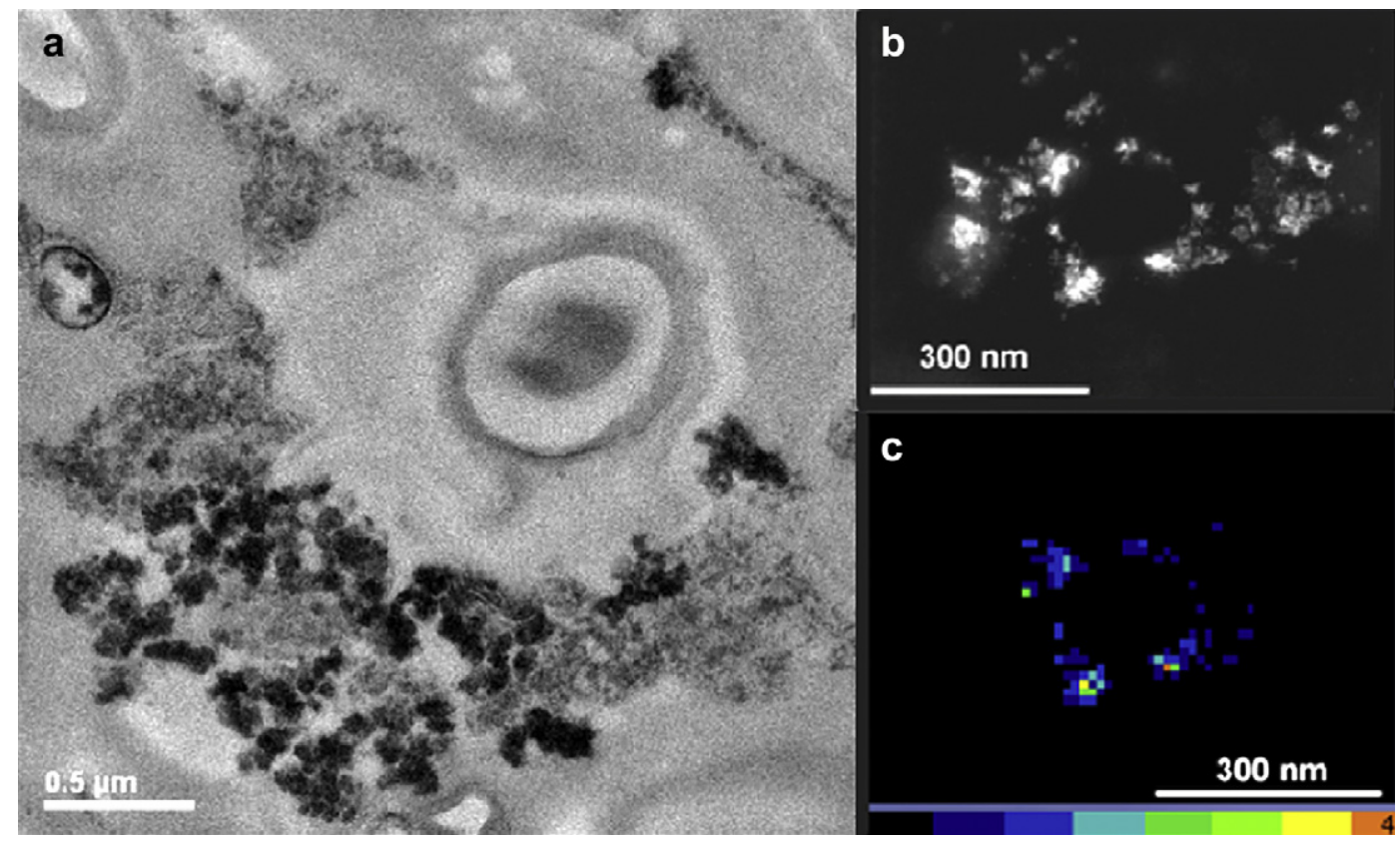

Fig. 3. TEM image (a) and STEM image (b) of spores surrounded by precipitates; elemental U EDS map (c) indicating U localization around the spores that reduced $\mathrm{U}(\mathrm{VI})$.

The recent discovery of the ability of D. reducens, a Grampositive bacterium belonging to the Clostridiales family, to reduce $\mathrm{U}(\mathrm{VI})$ both in the vegetative state and in the metabolically dormant sporulated state (Junier et al., 2009) stimulated the investigation of the capacity of spores of other species for which the vegetative cells are known to reduce U(VI) to do the same. Here, we report that $C$. acetobutylicum spores are also capable of driving $\mathrm{U}(\mathrm{VI})$ reduction (Fig. 1). While both D. reducens and C. acetobutylicum belong to the Clostridiales family of the Firmicutes, they are metabolically distinct because species in the genus Desulfotomaculum have acquired the capacity to respire $\mathrm{SO}_{4}^{2-}$, thus widening the range of their nutritional strategies, whereas species of Clostridium are strictly fermentative. It is remarkable that both of the strains tested for $\mathrm{U}(\mathrm{VI})$ reduction exhibited that ability and this finding raises the possibility that metal reduction may be a more widespread capacity among spores than currently recognized.

The ability of spores to reduce U(VI) is novel, since bacterial spores are generally considered to be metabolically dormant and not to modify the chemical conditions of the surrounding environment. The only previous evidence of redox-active spores is the case of Bacillus SG-1 spores, able to oxidize $\mathrm{Mn}(\mathrm{II})$ to $\mathrm{Mn}(\mathrm{IV})$ and precipitate $\mathrm{Mn}(\mathrm{IV}) \mathrm{O}_{2}$ onto their surface (Rosson and Nealson, 1982).

The spores of $C$. acetobutylicum appear to be able to catalyze the reduction of $\mathrm{U}(\mathrm{VI})$ only under specific chemical conditions. In fact, fresh growth medium, deprived of growthsustaining electron donors, or simple chemical media (BP) did not support this process. Reduction only took place when the spores were suspended in the spent medium from vegetative cell growth amended with $\mathrm{H}_{2}$ as an electron donor (Fig. 1). This suggests that, during growth, cells of $C$. acetobutylicum release a compound that is capable of stimulating reduction. The most likely hypothesis on the nature of this soluble factor is that it is an electron shuttle that serves as an intermediate in multi-step transport of electrons from $\mathrm{H}_{2}$ to $\mathrm{U}(\mathrm{VI})$. The requirement for this factor is consistent with what was found for $D$. reducens, whose spores were also only capable of reducing $\mathrm{U}(\mathrm{VI})$ in the spent medium from the growth of its vegetative cells (Junier et al., 2009). However, the spores of the former were unable to reduce U(VI) in spent medium from a D. reducens culture (spent WLP) (Fig. 1). This result indicates that the soluble factors released during growth by the vegetative cells of $C$. acetobutylicum and $D$. reducens are different, and that the factor secreted by $D$. reducens is not functional in the presence of $C$. acetobutylicum spores. Thus, it appears as though the factor is genus-specific. It is not possible to test the capability of $D$. reducens spores in spent FLP, since this medium leads to spore germination due to the presence of growth-sustaining nutrients (i.e., butyrate as electron donor, sulfate as electron acceptor).

The product of $\mathrm{U}(\mathrm{VI})$ reduction by $C$. acetobutylicum cells and spores was identified by XAS to be a mixture of $\mathrm{UO}_{2}$ and other U(IV) products including adsorbed U(IV) species (Bernier-Latmani et al., submitted for publication). In contrast, D. reducens did not form any detectable $\mathrm{UO}_{2}$ as a product. This finding, which is in contrast to what is commonly considered to be the product of $\mathrm{U}(\mathrm{VI})$ reduction by bacteria, i.e., $\mathrm{UO}_{2}$, does not, however, appear to be a direct consequence of biological features. Bernier-Latmani et al. (submitted for publication), show that the product of $\mathrm{U}(\mathrm{VI})$ reduction is mainly determined by the chemical environment which supports the reduction.

The biochemical mechanism by which the spores of C. acetobutylicum reduce $\mathrm{U}(\mathrm{VI})$ has not been characterized, and thus the proteins involved in the electron transfer from the electron donor to U(VI) have not been identified. Hypotheses on the localization of this/these protein(s) can be proposed by the observation of electron micrographs of the spores after 


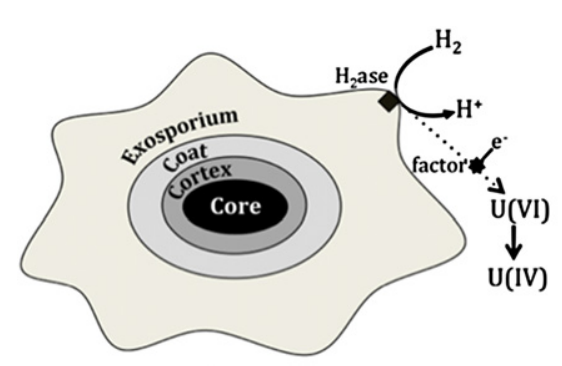

a

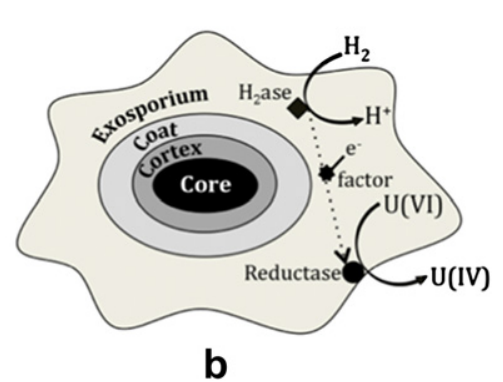

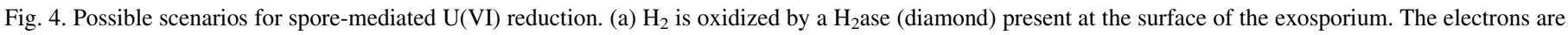

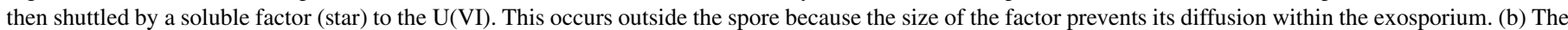

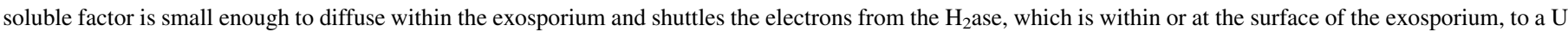

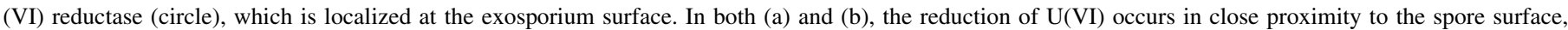
leading to U(IV) precipitation outside the exosporium.

reduction. Because $\mathrm{U}(\mathrm{IV})$ is highly insoluble and is not expected to diffuse away from the site of its reduction, the localization of reduced U(IV) should correspond to the physical location of the reduction process. TEM images (Fig. 3) show that U(IV) is localized on the outer surface of the exosporium. There are two possible scenarios that would support this finding: (a) $\mathrm{H}_{2}$ (the electron donor) is oxidized within the exosporium or at its outer surface by a hydrogenase. Electrons released from oxidation could reduce a soluble factor (that, in this scenario, is present outside the exosporium because it is too large to diffuse through exosporium pores). In turn, the factor could reduce $\mathrm{U}(\mathrm{VI})$ which precipitates as $\mathrm{U}(\mathrm{IV})$ at the edge of the exosporium (Fig. 4a); or (b) a $\mathrm{U}(\mathrm{VI})$ reductase is localized on the outer surface of the exosporium and $\mathrm{H}_{2}$ oxidation is catalyzed within the exosporium. Electrons are shuttled from the hydrogenase to the reductase by the factor (which, in this scenario, is small enough to diffuse within the exosporium) (Fig. 4b). Because the size of the factor is unknown, it is currently not possible to evaluate the relative likelihood of these two hypotheses.

Both possibilities are supported by the finding that $\mathrm{Mn}(\mathrm{II})$ oxidase in the Bacillus SG-1 spores, a multicopper oxidase called MnxG, is localized in the exosporium (Francis et al., 2002). In contrast, for $D$. reducens spores, the product of $\mathrm{U}(\mathrm{VI})$ reduction was found to accumulate both within the exosporium and on the spore coat (Junier et al., 2009). Furthermore, the morphology of $D$. reducens spores appears to be significantly altered after U(VI) reduction as the exosporium appears to be distorted (P. Junier, unpublished data) and that is not the case for $C$. acetobutylicum spores (Fig. 3). These observations point to subtle differences in the mechanism of $\mathrm{U}(\mathrm{VI})$ reduction by $D$. reducens and $C$. acetobutylicum, but support the general conclusion that at least a spore component, a soluble factor and $\mathrm{H}_{2}$ are needed for spore-mediated U(VI) reduction. In the case of both organisms, further investigation is necessary to be able to describe the biochemical process responsible for the reduction and precipitation of uranium. In particular, fractionation of the spore layers, primarily exosporium and coat, and testing each for U(VI) reduction activity, followed by protein purification are essential steps for the characterization of the reaction and identification of the proteins involved.
The findings unveiled to date point towards mechanisms of reduction with shared similarities among Gram-positive sporeforming bacteria, but that are distinct from that described for the Gram-negative model organisms. In this respect, it would be worth testing the redox activity of spores of other U(VI)reducing bacteria phylogenetically close to the Clostridia, such as C. pasteurianum, C. sphenoides and Desulfosporosinus orientis.

The finding of $\mathrm{U}(\mathrm{VI})$ reduction activity in the spores of two Gram-positive bacteria is of great interest both from a biochemical point of view, for the novelty of a reduction process catalyzed by spores, and from an environmental point of view. In addition to the need for an in-depth characterization of the enzymatic process and the biological requirements for the reaction to occur (i.e., identification of the unknown factor in the spent medium), it will be important to evaluate the relevance of spore-mediated reactions in the environment. Should the reduction of $\mathrm{U}(\mathrm{VI})$ by spores be found to be dominant in contaminated sites, it may be necessary to reconsider bioremediation strategies.

\section{Acknowledgements}

This research was supported by the Swiss National Science Foundation, grant \#315230_127546/1 and by the Roche Research Foundation through a fellowship to EDV. Electron microscopy facilities were provided by the Interdisciplinary Electron Microscopy Center (CIME) at EPFL. ICP-OES measurements were carried out at the Central Environmental Laboratory at EPFL.

\section{References}

Bencheikh-Latmani, R., Williams, S.M., Haucke, L., Criddle, C.S., Wu, L.Y., Zhou, J.Z., Tebo, B.M., 2005. Global transcriptional profiling of Shewanella oneidensis MR-1 during $\mathrm{Cr}(\mathrm{VI})$ and $\mathrm{U}(\mathrm{VI})$ reduction. Appl. Environ. Microbiol. 71, 7453-7460.

Bernier-Latmani, R., Veeramani, H., Dalla Vecchia, E., Junier, P., Lezama, J., Suvorova, E., Sharp, J.O., Stubbs, J.E., et al. Non-uraninite products of microbial U(VI) reduction. Environ. Sci. Technol. submitted for publication. 
Chang, Y.J., Peacock, A.D., Long, P.E., Stephen, J.R., McKinley, J.P., Macnaughton, S.J., Hussain, A.K.M.A., Saxton, A.M., et al., 2001. Diversity and characterization of sulfate-reducing bacteria in groundwater at a uranium mill tailings site. Appl. Environ. Microbiol. 67, 3149-3160.

Dong, W.M., Xie, G.B., Miller, T.R., Franklin, M.P., Oxenberg, T.P., Bouwer, E.J., Ball, W.P., Halden, R.U., 2006. Sorption and bioreduction of hexavalent uranium at a military facility by the Chesapeake Bay. Environ. Pollut. 142, 132-142.

Francis, A.J., Dodge, C.J., 2008. Bioreduction of uranium(VI) complexed with citric acid by Clostridia affects its structure and solubility. Environ. Sci. Technol. 42, 8277-8282.

Francis, A.J., Dodge, C.J., Gillow, J.B., 1992. Anaerobic microbial transformations of uranium and toxic metals in wastes. J. Am. Chem. Soc. 203 172-GEOC.

Francis, A.J., Dodge, C.J., Lu, F.L., Halada, G.P., Clayton, C.R., 1994. XPS and XANES studies of uranium reduction by Clostridium sp. Environ. Sci. Technol. 28, 636-639.

Francis, C.A., Casciotti, K.L., Tebo, B.M., 2002. Localization of Mn(II)oxidizing activity and the putative multicopper oxidase, MnxG, to the exosporium of the marine Bacillus sp strain SG-1. Arch. Microbiol. 178, $450-456$.

Gao, W.M., Francis, A.J., 2008. Reduction of uranium(VI) to uranium(IV) by Clostridia. Appl. Environ. Microbiol. 74, 4580-4584.

Gavrilescu, M., Pavel, L.V., Cretescu, I., 2009. Characterization and remediation of soils contaminated with uranium. J. Hazard. Mater. 163, 475-510.

Junier, P., Frutschi, M., Wigginton, N.S., Schofield, E.J., Bargar, J.R., BernierLatmani, R., 2009. Metal reduction by spores of Desulfotomaculum reducens. Environ. Microbiol. 11, 3007-3017.

Kashefi, K., Lovley, D.R., 2000. Reduction of Fe(III), Mn(IV), and toxic metals at 100 degrees $\mathrm{C}$ by Pyrobaculum islandicum. Appl. Environ. Microbiol. 66, 1050-1056.

Khijniak, T.V., Slobodkin, A.I., Coker, V., Renshaw, J.C., Livens, F.R., BonchOsmolovskaya, E.A., Birkeland, N.K., Medvedeva-Lyalikova, N.N., et al., 2005. Reduction of uranium(VI) phosphate during growth of the thermophilic bacterium Thermoterrabacterium ferrireducens. Appl. Environ. Microbiol. 71, 6423-6426.

Lovley, D.R., Phillips, E.J.P., 1992. Bioremediation of uranium contamination with enzymatic uranium reduction. Environ. Sci. Technol. 26, 2228-2234.

Lovley, D.R., Phillips, E.J.P., Gorby, Y.A., Landa, E.R., 1991. Microbial reduction of uranium. Nature 350, 413-416.
N'Guessan, A.L., Vrionis, H.A., Resch, C.T., Long, P.E., Lovley, D.R., 2008. Sustained removal of uranium from contaminated groundwater following stimulation of dissimilatory metal reduction. Environ. Sci. Technol. 42, 2999-3004.

Payne, R.B., Casalot, L., Rivere, T., Terry, J.H., Larsen, L., Giles, B.J., Wall, J. D., 2004. Interaction between uranium and the cytochrome $\mathrm{c}(3)$ of Desulfovibrio desulfuricans strain G20. Arch. Microbiol. 181, 398-406.

Roh, Y., Liu, S.V., Li, G.S., Huang, H.S., Phelps, T.J., Zhou, J.Z., 2002. Isolation and characterization of metal-reducing Thermoanaerobacter strains from deep subsurface environments of the Piceance Basin, Colorado. Appl. Environ. Microbiol. 68, 6013-6020.

Rosson, R.A., Nealson, K.H., 1982. Manganese binding and oxidation by spores of a marine Bacillus. J. Bacteriol. 151, 1027-1034.

Shelobolina, E.S., Coppi, M.V., Korenevsky, A.A., DiDonato, L.N., Sullivan, S.A., Konishi, H., Xu, H.F., Leang, C., et al., 2007. Importance of c-type cytochromes for $\mathrm{U}(\mathrm{VI})$ reduction by Geobacter sulfurreducens. BMC Microbiol. 7 (16).

Suzuki, Y., Banfield, J.F., 2004. Resistance to, and accumulation of, uranium by bacteria from a uranium-contaminated site. Geomicrobiol. J. 21, $113-121$.

Suzuki, Y., Kelly, S.D., Kemner, K.M., Banfield, J.F., 2002. Microbial populations stimulated for hexavalent uranium reduction in uranium mine sediment. Appl. Environ. Microbiol. 69, 1337-1346.

Suzuki, Y., Kelly, S.D., Kemner, K.M., Banfield, J.F., 2004. Enzymatic U(VI) reduction by Desulfosporosinus species. Radiochim. Acta 92, 11-16.

Tebo, B.M., Obraztsova, A.Y., 1998. Sulfate-reducing bacterium grows with $\mathrm{Cr}(\mathrm{VI}), \mathrm{U}(\mathrm{VI}), \mathrm{Mn}(\mathrm{IV})$, and $\mathrm{Fe}(\mathrm{III})$ as electron acceptors. FEMS Microbiol. Lett. 162, 193-198.

Thomas, S.H., Sanford, R.A., Amos, B.K., Leigh, M.B., Cardenas, E., Loffler, F.E., 2010. Unique ecophysiology among U(VI)-reducing bacteria as revealed by evaluation of oxygen metabolism in Anaeromyxobacter dehalogenans Strain 2CP-C. Appl. Environ. Microbiol. 76, 176-183.

Wall, J.D., Krumholz, L.R., 2006. Uranium reduction. Annu. Rev. Microbiol. $60,149-166$

Wu, Q., Sanford, R.A., Loffler, F.E., 2006. Uranium(VI) reduction by Anaeromyxobacter dehalogenans strain 2CP-C. Appl. Environ. Microbiol. 72, $3608-3614$.

Yang, W.W., Crow-Willard, E.N., Ponce, A., 2009. Production and characterization of pure Clostridium spore suspensions. J. Appl. Microbiol 106, $27-33$. 